Tavares, Fátima. Alquimistas da Cura: a rede terapêutica alternativa em contextos urbanos. Salvador: UFBA, 2012, 224pp.

\title{
ENERGIA, HOLISMO E MÍSTICA: A REDE TERAPÊUTICA ALTERNATIVA NO Rio DE JANEIRo
}

\author{
Rodrigo Toniol
}

Durante a década de 1990, foram realizadas importantes pesquisas no Brasil sobre o campo das terapias alternativas (Russo 1993'; Magnani 1999²; Martins 199933; Amaral 20004; entre outros). Esses textos, agora já referências incontornáveis na área, sublinharam distintos aspectos desse universo bastante heterodoxo e permitiram o reconhecimento de alguns traços comuns aos terapeutas, às terapias e aos próprios usuários dessas práticas. Em que pese o caráter sempre provisório das sínteses sobre tais contextos, marcados por uma dinâmica intensa de surgimento de novas terapias e, por conseguinte, de terapeutas e de público-alvo, as pesquisas convergiam na afirmação de que o recurso às "medicinas alternativas" não se constituía como um fenômeno passageiro ou situacional, mas como algo duradouro e sustentado por uma complexa e extensa rede capaz de agregar centros de formação, mercado esotérico, clínicas e grupos espiritualistas.

A recente publicação do livro Alquimistas da cura: a rede terapêutica alternativa em contextos urbanos, de Fátima Tavares é um exemplo tanto da permanência do tema na agenda de pesquisa das ciências sociais, como também da atualidade do próprio fenômeno social de consolidação das terapias alternativas no país. Produzido a princípio como uma tese de doutorado (defendida em 1998 no Programa de Pós-Graduação em Sociologia e Antropologia da Universidade Federal do Rio de Janeiro), a atual edição em forma de livro consegue preservar o frescor da pesquisa, de maneira que, passados quinze anos desde sua primeira escrita, os aportes analíticos, teóricos e metodológicos presentes no texto permanecem em plena vigência.

A investigação dirige-se ao trabalho dos terapeutas e suas associações com um universo amplo e difuso de orientações religiosas, filosóficas, místicas e esotéricas implicado nesse modo "alternativo" de conceber o binômio saúdedoença. Interessam, portanto, menos os matizes entre cada uma das diversas terapêuticas com as quais os profissionais pesquisados trabalham, que o modo 
pelo qual as trajetórias desses terapeutas implicaram na produção de associações entre determinadas técnicas e outros aspectos do chamado "universo alternativo".

O livro, estruturado em sete capítulos e uma conclusão, apresenta esse campo de pesquisa a partir de questões que atravessam as distintas trajetórias abordadas, tais como: as disputas em torno da profissionalização dos terapeutas; da legitimação das terapias; e a apresentação dessas práticas em jornais especializados. O material empírico que serviu de base para o livro de Fátima Tavares é composto tanto de entrevistas e observações em certos espaços terapêuticos, como da produção escrita sobre essas terapias.

Diante de um universo de práticas atravessado por referentes diversos cujo poder de nominar algo como terapêutico ou mesmo de se apresentar como terapeuta é, antes de tudo, uma ação política, a autora optou por caracterizar seu universo de investigação a partir de uma negação dupla ${ }^{5}$ : primeiro, por se tratar de um contexto que se afasta daquilo que poderíamos reconhecer como uma "gestão religiosa da cura" - ou seja, de rituais e práticas dirigidos à resolução de problemas de saúde administrados no âmbito de instituições religiosas ${ }^{6}$ - e segundo, por outra negação demarcadora de seu contexto de pesquisa que é a dissociação em relação ao paradigma biomédico hegemônico nas sociedades ocidentais. A autora situa a rede terapêutica alternativa numa nebulosa místicoesotérica cujas práticas, embora não estejam necessariamente circunscritas a referências new age, com elas se articulam e se adensam.

No que se refere aos profissionais que operacionalizam esse universo discursivo heterogêneo e dão a ele concretude a partir de práticas terapêuticas, a autora sugere a existência de algumas orientações gerais. Trata-se, por um lado, de um contexto significativamente tensionado por dois modelos de legitimidade terapêutica: um deles, característico do campo biomédico (os exames clínicos e tecnológicos capazes de comprovar a eficácia de uma terapêutica); e outro, próprio de contextos mágico-religiosos (as comprovações espirituais, kármicas etc. de uma melhora na saúde). Por outro lado, também operando como um princípio orientador dos terapeutas, está a utilização de determinados princípios para explicar o processo de saúde-doença (seriam eles: holístico, energético, vibracional/frequencial e terapêutico). A autora explora os diferentes modos pelos quais cada uma dessas categorias aparece - seja em narrativas de terapeutas ou em artigos e jornais especializados - relacionada com as terapias alternativas.

Não me ocuparei aqui de reproduzir as nuances sugeridas sobre o uso de cada uma dessas categorias, mas trato de sublinhar o modo pelo qual a dinâmica da rede terapêutica alternativa nos últimos anos - posteriores à escrita original do texto implicou em alguns deslocamentos importantes. Um primeiro termo mais recentemente incorporado como recurso explicativo do binômio saúde-doença no contexto alternativo parece ter sido o de "natureza". Embora usado de maneira polissêmica, o termo tem se tornado um descritor de um estado de equilíbrio energético desejado, 
saudável. A busca pela "natureza do sujeito" está no horizonte de diversas terapias alternativas e tem se consolidado discursivamente como um marcador de um gradiente de estados de adoecimento e cura. Outro termo que tem ganhado centralidade na produção de marcos definidores das terapias alternativas refere-se às "Práticas Integrativas e Complementares" (PICs) ${ }^{7}$, cujo uso associa-se a um processo político de legitimação das terapias alternativas e a consequente necessidade de ênfase na ideia de complementariedade - em detrimento da nomenclatura de alternativo. Tal nomeação, ao que parece, acompanha o processo de institucionalização das terapias alternativas, revelando uma tendência para amenizar disputas com associações médicas ${ }^{8}$.

Em outro esforço de classificação central para o desenvolvimento de sua análise, Fátima Tavares sugere a existência de modelos terapêuticos distintos que poderiam ser divididos entre tratamentos convencionais, tratamentos alternativos, esoterismo e outros. Nesse passo, a autora esclarece uma distinção entre "técnicas de diagnóstico" e "técnicas de tratamento": na primeira, estariam incluídas práticas como o uso de pêndulo radiestésico, por exemplo; e na segunda, localizam-se as práticas interventivas (como florais e fitoterapia, por exemplo). Talvez um dos fenômenos mais interessantes relativos a essa categorização seja, justamente, aquele que explicita passagens de uma categoria a outra, como é o caso do tarot terapêutico, já explorado em artigos específicos (Tavares 1999).

De um modo bastante profícuo a autora elabora de diferentes maneiras uma articulação entre reflexões sobre os terapeutas e sobre as características das terapias. A importância da realização desse tipo de descrição reside no fato de que o uso de determinadas terapias está intimamente relacionado com a trajetória do terapeuta que a utiliza, não somente por conta da formação específica do sujeito, mas, sobretudo, por conta das articulações entre distintas terapias aplicadas em um mesmo procedimento. De alguma maneira, é a partir dos diferentes modos de associar e executar as terapias que a autora apresenta as múltiplas possibilidades de trajetórias dos terapeutas. A partir dessas articulações no binômio terapeuta-terapia podemos elaborar agrupamentos, sugeridos por Fátima Tavares, como o dos terapeutas que dão ênfase numa "habilidade profissionalmente adquirida" e aqueles que investem na ideia de um dom anterior à prática terapêutica, mas melhor desenvolvido a partir de um processo de formação.

A tentativa de reconstituição da rede terapêutica alternativa é realizada a partir da trajetória de diferentes agentes. Chama atenção nessas trajetórias a crescente profissionalização no campo, que tende a ser paulatinamente dissociado do âmbito da nebulosa místico-esotérica e aproximado do universo "terapêutico dos especialistas". Embora esse movimento possa ser enunciado como uma tendência mais ampla, ele pode ser nuançado de acordo com a entrada do terapeuta na rede e com a qualificação de seu perfil podendo ser mais psicologizante (menor número de técnicas; pragmatismo racionalizante; habilidade 
adquirida e proeminência da profissão à vocação; menor experimentação religiosa) ou mais espiritualizantes (maior número de técnicas; pragmatismo místico; proeminência do dom anterior à habilidade adquirida, da vocação à profissão).

A autora também investe na diversidade de espaços destinados a essas práticas. A partir de uma caracterização desses ambientes, ora próximos a espaços hospitalares, ora mais afins a centros de espiritualidade esotérica, é possível acompanhar processos históricos de transformações nas tendências da rede terapêutica no Rio de Janeiro. A diversidade das experiências da rede de terapias alternativas é visibilizada por Fátima Tavares a partir de uma polarização narrativa entre um espaço urbano, com a oferta de diferentes terapias e cujo público está associado às classes sociais mais abastadas e escolarizadas; e um espaço no interior do estado do Rio de Janeiro em que ocorre a administração exclusiva de um medicamento fitoterápico, por uma mulher que passou a produzi-lo a partir de uma experiência onírica em que fora instruída sobre o modo de preparo e sobre sua missão a partir de então. O que está em jogo nessa polarização, além de uma rica descrição da heterogeneidade do universo investigado, é o acirramento entre modos distintos de se situar nessa rede capaz de abrigar terapeutas cada vez mais dispostos a afirmar os processos de especialização pelos quais passaram até chegar à profissionalização, e também aqueles terapeutas que não reclamam o título de especialistas, mas enfatizam a autenticidade de seu dom e a validade do conhecimento popular.

Em sua conclusão, Fátima Tavares elabora um inventivo esquema, denominado "continuum terapêutico", cuja função é demarcar algumas descontinuidades nos modelos de referência e de legitimação das terapias e dos terapeutas. A produção de uma síntese para esse contexto tão diverso, ainda que provisória, não poderia deixar de encarnar o aspecto ambíguo em que o contínuo e o descontínuo não somente são relacionais, como também sobrepostos. Nesse esquema, a autora apresenta, de um lado, um campo chamado de "extramédico" e, de outro, um campo "paramédico"10: o primeiro está associado às terapêuticas mágico-religiosas, e nele os terapeutas tem uma trajetória fundada no dom e a cura é, no limite, milagrosa (aí estariam incluídos a medicina popular e a cura religiosa); o segundo, tem referências modernas (que pouco legitimam o tradicional), e nele a ideia de energia tem centralidade - os terapeutas são especialistas e a cura é científica (nesse campo estariam tanto as medicinas alternativas, como as medicinas fundadas em um saber biomédico).

Embora seja uma publicação tardia - mais de uma década depois da defesa da tese da qual se originou -, Alquimistas da Cura chega aos leitores em um momento muito oportuno, de crescente legitimação das terapias alternativas. Sem perder de vista os contextos empíricos investigados, Fátima Tavares consegue apresentar questões de ordem teórica e metodológica importantes para a complexificação desse universo que não cessa de se diversificar e de ser 
atravessado por novos agentes. Nesse contexto, torna-se candente a realização de esforços analíticos para a compreensão das novas dinâmicas dessa rede terapêutica alternativa cuja utilização tem se ampliado a passos largos fazendo emergir novos perfis de terapias, de terapeutas e de usuários.

\section{Notas}

1 RUSSO, Jane Araújo. (1993), O corpo contra a palavra : as terapiascorporais no campo psicológico dos anos 1980. Rio de Janeiro: EdUFRJ.

2 MAGNANI, José Guilherme Cantor. (1999), Mystica urbe: um estudo antropológico sobre o circuito neo-esotérico na metrópole. São Paulo: Studio Nobel.

3 MARTINS, Paulo Henrique. (1999), "As terapias alternativas e a libertação dos corpos". In: J. M. Carozzi (org.). A nova era no Mercosul. Petrópolis: Vozes.

4 AMARAL, Leila. (2000), Carnaval da alma: comunidade, essência e sincretismo nova era. Petrópolis: Vozes.

5 Não são poucos os processos no Brasil movidos por entidades de classes médicas contra escolas de terapias alternativas e mesmo contra terapeutas. Levando em conta somente aqueles motivados pelo uso do termo medicina por não médicos, pude encontrar, em setembro de 2012, no Tribunal de Justiça do Rio Grande do Sul, cinco processos em tramitação.

6 Somente para citar algumas das diversas pesquisas desenvolvidas no Brasil sobre tratamentos de saúde em contextos religiosos, ver: NEVES, Delma. (1984), As "curas milagrosas" e a idealização da ordem social. Niterói: EdUFF; MONTERO, Paula. (1985), Da doença à desordem: a magia na Umbanda. Rio de Janeiro: Graal; MALUF, Sônia. (1996), Les Enfants du verse au pays des terreiros: Les Cultures thérapeutiques et spirituelles alternatives au sud du Brésil. Paris: Tese de doutorado em Antropologia Social e Etnologia, EHESS; RABELO, Miriam C. et al. (1998), "Comparando experiências de aflição e tratamento no candomblé, pentecostalismo e espiritismo". In: Anais do XXII encontro anual da ANPOCS. Caxambu: ANPOCS; GOMBERG, Estélio. (2011), Hospital de orixás: encontros terapêuticos em um terreiro de candomblé. Salvador: EdUFBA.

7 Sobre essa maior visibilização do termo "Práticas Integrativas e Complementares", ver: BAER, Hans. (2010), "Complementary and Alternative Medicine Processes of Legimation, Professionalization, and Cooption". In: W. Cockerham. Medical Sociology. Oxford: Wilwy-Blackwell.

8 Em 2006, uma comissão interministerial lançou a Política de Práticas Integrativas e Complementares no âmbito do Sistema Único de Saúde. Trata-se da regulação e promoção da fitoterapia, homeopatia, termalismo, medicina chinesa e medicina antroposófica no sistema oficial e público de saúde brasileiro. A partir do lançamento dessa política, pode-se observar uma série de reações por parte de sindicatos e associações médicas.

9 TAVARES, Fátima. (1999), "Tornando-se tarólogo: percepção 'racional' versus percepção 'intuitiva' entre os iniciantes no tarot no Rio de Janeiro". Numem, v. 2, no 1: 97-123.

${ }^{10}$ Esses termos são tributários do livro pioneiro sobre medicinas alternativas: LAPLANTINE, François \& RABEYRON, Paul-Louis. (1991), Medicinas paralelas. São Paulo: Brasiliense.

\section{Rodrigo Toniol (rodrigo.toniol@gmail.com)}

Doutorando em Antropologia Social pelo Programa de Pós-Graduação em Antropologia Social da Universidade Federal do Rio Grande do Sul/UFRGS. 